\title{
A GENERAL OUTLOOK OF CONJUGAL UNION AND MARRIAGE IN TURKEY IN THE CONTEXT OF POPULAR CULTURE, NEW MEDIA*
}

\author{
Öykü Ezgi YILDIZ \\ İstanbul Kültür University, Turkey \\ e.yildiz@iku.edu.tr \\ Ceyda DENEÇLİ \\ İstanbul Kültür University, Turkey \\ c.denecli@iku.edu.tr \\ Sevda DENEÇLİ \\ Marmara University, Turkey \\ sevdadenecli@hotmail.com
}

\begin{abstract}
In our time, in which social lifeturnes spiritual values into a market, local standards of judgement, human relations and conjugal union has been influenced by this change, also. In our time, conjugal union, which is still seen as a taboo in Turkish society, has become a market with the influence of popular culture. Conjugal union, which has the characteristics of a social institution in our ime, benefits from the opportunities of technology in direct proportion to globalization and new technological developments, while trying to preserve its traditional features at the same time. In this transformation process, various media organs, socialization agents on media tools such as marriage websites play a significant role. In this study, the process of how conjugal union, which is shaped by the direct influence of popular culture, goes through a change in the direction of global market mentality will be discussed and a research will be made on the basis of social media agents.
\end{abstract}

Keywords: Popular Culture, Consumerist Society, Social Media, Conjugal Union, New Media, Marriage

\section{INTRODUCTION}

The development of new media mediums and the place of the internet in individuals' life in the $21^{\text {st }}$ century is one of the breakthroughs in human history. Conventional media has the power to shape social life and now new media platforms have adjoined to this certain power. Emergence of interactive communication platform, with all above, has affected individuals' socialization process and communication among people. Especially, as the internet has become one of the focus points of our lives, our perception of environment and other people has changed. While the boundaries among individuals, in a sense, abolished, the distances have expanded.

Individuals, who are making use of new media platforms and interactive communication, have the opportunity to be aware of the developments all around the world and they can also share their feelings and opinions with others in an easy and free way. In spite of all the attractive contributions it has brought, the Internet is not perceived positively by all communities and criticized both favorably and unfavorably. Therefore, it would be useful to describe some certain concepts so as to understand the Internet platform and socialization forms appearing on this platform.

\section{New Media, Internet and The Impact of the Internet on Socialization}

\footnotetext{
* Presented on $9^{\text {th }}$ Annual International Conference on Communication and Mass Media, Athens, 2011.
} 
New media forms are important as they have the capacity to reshape the life in general, social relations and free time activities (Leung and Lee; 2004) New media is a digitization fact that enables sound, data, text and image being conveyed, preserved, collected and put in process over one infrastructure. Digitization is the state of information being put into format which is computer readable. The biggest advantage digitization in new media offers is that; since the numerical information is expressed through electrical figures, it can be used, exchanged and conveyed from one platform to other by other electronic devices. GSM, WAP, GPRS, CD, VCD, DVD interactive CD, double-sided CD are all forms of new media and they all have been produced by digital technology. (Aktaş, 2007) The Internet, one of new media forms, has become one of the powerful mass media medium which shapes social life. The Internet, which has changed both the way of communication among people and their socialization forms, has also attracted the attention of institutions as a platform of advertisement.

Banners, pop-ups, sponsorship, e-mail etc. are all available advertisement forms on the Internet platform. People can watch programs, read newspapers, listen to the radio, check their e-mails and can see the advertisements through the Internet. Therefore, the Internet is a hybrid form of advertisement platforms such as television, newspaper, radio, magazine and direct mail. The Internet can be used like the conventional media in means of getting information and entertainment (Cho \& Cheon, 2004).

This fast and unstoppable development of the media and technology, the appearance of new media forms, the internet becoming an effective communication tool, has, in fact, not abolished conventional communication ways and life styles. However, it has made major changes in traditional life styles in some certain aspects. First of all, due to the development of communication media, the establishment and pervasion of the tradition has become increasingly dependent on communication styles that are not face to face (Thompson, 2008).

As we have seen, the development of information and communication technologies are the driving forces for the mass media forms taking place of face to face communication. Today, the communication among individuals and mass communication taking place over the Internet is called as cyber society. This communication platforms are referred as cyber since the unification among the individuals are not dependent on certain physical conditions, time and space (Dijk, 1999).

Recently, communication over cyber platform gained importance and has actually been a turning point. In past, the communication among individuals and socialization process was the outcome of people's coming together, however due to technological devices shaping $21^{\text {st }}$ century people's lives, now it has new dimensions. The Internet has non-negligible effects on social relations. The Internet, connecting people through webs and making the distances closer, also affects peoples' romantic relations and has become a tool to pick up partners. This huge effect of the Internet on $21^{\text {st }}$ century individuals has also attracted the attention of researchers who have different ideas about its use as a mass communication tool and socialization platform. Whereas some researchers have negative attitudes toward the Internet, some are positive about it. It would be good to have a look at the studies of these researches so as to understand the effects of the Internet on family, marriage and socialization process which are the basics of social structure.

Parks and Floyd (1995), for instance, have examined the world built through discussion groups on the Internet. This research, including a questionnaire as well, examines the development of communication between people who are in touch in news group on the Internet. The research demonstrates that relations among these people have a certain sincerity and depth as it is in face to face communication. In McKenna's (2002), 600 people are picked up randomly from news groups discussing about politics, fashion, health, astronomy, computer. In this research, it has been pointed out that an important ratio of the participants have a close dialogue with the people they met on the Internet. Another result of the research 
is that people in these news groups also have relations in real life. More then fifty percent of the participants have met individually. Furthermore, twenty two percent of the participants have turned their relations to romantic affairs; engagements and marriages have indeed occurred. All the participants have been examined for two years and it has been understood that their relations have turned into consistent friendships and relations as the conventional ones (Bargh \& McKenna, 2004).

In 1990s, theorists developed ideas about the negative and positive impacts of the Internet on social relations as the Internet became the major medium of social encountering. Zuboff, for instance, claims that "the Internet decreases face to face communication," for the people at work," and "it creates a worrying loneliness," However, Terine Raney (2000) claims that online communication contributes to social webs. Pew Internet and American Life Projected conducted a research based on Raney's findings. The participants told that using emails strengthen family relations; this was a supporting evidence for Raney's opinions about the Internet. Cooper and Sportolari mention that there is a common belief about relations formed on digital platform causing emotional disconnection and they put forward the idea that online relations positively contribute to individual relations such as romantic affairs (Lawson \& Kira leck,2006).

\section{The concept of matchmaking and Romantic Interaction on the Internet}

With the appearance of the Internet not only face to face communication but also romantic relations have changed dimensionally. Since the daily life is hectic and complex nowadays and cyber platforms are more at the center in individuals' lives; romantic online affairs become pervasive and usual. Therefore, the Internet took place of the matchmakers who used to introduce people to each other. However, this concept, the origin of which goes back to the past, kept developing by making use of various mediums. It is sometimes the individuals, sometimes conventional media and sometimes the Internet that form the matchmaking process. The demand for the websites enabling people to have romantic affairs causes to perceive marriage institution as a market. In order to understand how this kind of service became a market, we need to go through how this service provided through the dating websites and television developed in time.

Matchmaking is not a new concept. In fact, its origin goes back to mid nineteen century. Matchmaking, a kind of personal advertisement, initially took its place in newspapers. In 1980 s, video dating was a more popular medium in partner finding. Nowadays, the Internet provides a wider service; it offers huge opportunities to individuals so that they can advertise themselves (Ellison, Heino, \& Gibbs, 2006).

Online dating services are new profitable businesses of the Internet revolution that caused much contradiction. The Internet, which has the power to reach millions of people 24 hours a day, directed its online dating industry to billion dollar love stories for its customers. This successful story is shaped for the customers who can not fulfill their needs with conventional matchmaking methods. This considerable success of online dating phenomenon comes from its deliberate use of interference-based system in order to cope with customers' certain considerations arousing from conventional dating services. This recent enterprise, making use of the Web strategically, provides matchmaking web-sites that are appropriate, handy and credible (Smith, 2005). Websites similar to those which provide dating services based on the afore mentioned conscious matching have been providing service in Turkey as well as worlwide for nearly 10 years. When such websites in Turkey are analyzed, it is observed that starting point of these websites is United States. These websites spreaded to Europe and then all the world after US (Interview with director of evlilikmerkezi.com; Ebru Selvi).

Matchmaking web-sites follows a step by step process for the matches. Before offering suitable matches for the individuals, they collect credible information about the people. They specify their customers' special interests and hobbies with the help of certain forms. Then, 
they preserve and share this demographic information in accordance with the demands and expectations of the customers. In order to find suitable partners via the Internet, the profiles are formed by asking deterministic and selective questions to the users. The content of the questions are based on the lists specifying users' biographic data and expectations. Age, length, music and fashion interests are the priorities in these lists. The second step is to use a list reflecting individuals' expectations. All this data is used to form a list including suitable matches. Various methods are used to determine to find suitable matches. One way is to put in order similar individuals or to record similar answers. All this process is a mutual communication and the demands of all members are put in order by checking two sides (Smith,2005).

It is assumed that online communicators lack the information about the physical distance, common interaction, physical appearance, clues about group membership, and wide social context. However, while assumptions are reviewed again, a more positive attitude towards online communication among individuals' is observed. The lack of physical proximity and visual information is replaced by arranging a date, or sending photos or emails via the Internet (Parks \& Floyd, 1996).

The first Internet dating web sites appeared in mid 1990s offered their users only the opportunity to form make their profiles and search for their matches. Later, these web sites also offered different options such as webcast and instant message service. Some websites asked for more detailed profile information. Before internet dating, people used to meet in a more random way. Internet dating enabled single people to search for matches that they can have a better relation in a wider range of candidates. Online dating websites changed the ways of having relation in America. According to a research, every one person over six, gets married by meeting someone through the online dating web sites. (Brooks; 2011).

In our age, when competition is prominent in various platforms in every sector, marriage sector, which is gradually turning into a market, involves marriage websites as well. These websites take place among top 13 websites in the use of internet. Use of such friendship and marriage websites is quite common in Turkey. On the other hand, these websites have turned into a rapidly growing sector (Interview with director of evlilikmerkezi.com; Ebru Selvi). Like the websites in America, there are tv programs and Internet websites in Turkey offering similar services. These services offer a platform on which the individuals can meet their candidates, and a new market. Furthermore, they are the platforms in social life where the popular culture is combined with the conservative values.

\section{Marriage Institution and Finding a partner via the Internet}

Family, the base of social life, is undergoing through certain changes due to social changes. That is why we can claim that family which can be viewed as historical phenomena, has a dynamic structure. Family, which is at the center of social life, is reshaped in accordance with the conditions and requirements of the age. The major factors of family evolution are socialeconomic system and the properties of social relations (Ozankaya,2007).

Marriage, also described as the socially accepted sexual intercourse of the adults (Giddens,1997). has an important place in social life to maintain family institution. Marriage is a breakthrough in life and it establishes family institution which is the core of social life. Cultural structure of the societies, their production forms, economic structure, traditions, shortly all social differences are affective on the ways of getting married.

All societies have its own ways of getting married. That is why there are various ways of getting married all over the world. In Turkey, family arrangements, kidnapping the girl, marriage for money (money paid to the family of the woman),berder (exchanging the boys and girls of the same ages between two families), marriage by coincidence, meeting and 
getting married, marriage through the television (Sezen,2005), finding a partner via the Internet and getting married are some of the 30 different ways of getting married.

As we understand, in Turkey some of the marriages have more conservative structures whereas some of them are formed with the development of mass communication mediums and technology. Especially, marriage programs which have high ratings have increased in number as they draw a huge amount of interest of people. Besides television programs, various dating websites have turned into platforms that people of different origins, opinions, educational backgrounds make use of and interested in. Websites, the main goal of which are nor matchmaking such as facebook, twitter etc., can also be added to these modern matchmaking websites on the Internet.Traditional life style is still effective in Turkey and family arrangements is reformulated according to the developments in communication and information technologies and therefore new styles of marriages come along. Internet technology is an example to family arrangements settled on different mediums. Online dating websites are taking the place of families in family arrangement type of marriages (Özdoğan,2009).

Family arrangement type of marriages still exist in today's Turkey as it did before the Republic was founded. In past, families were involved in this process, today, however, television channels and internet websites take their places. Family arrangement marriage was a common way to establish family institution, especially before The Republic, and this type is still common, however, now throughout the technological benefits. Although family arrangement type of marriages is a result of conservative way of thinking, they have changed in means of form and content nowadays. The hectic life style of modern people caused these kind of arrangements to appear on mass communication tools. In order to understand family arrangement which has a different content now, we need to review the changes that Turkish family structure had undergone with the declaration of the Republic.

We do not have scientific researches that study Turkish family structure before the republic period. Most of the researches examining the family structure in Ottoman period are based on observations by foreigners. In these researches, the focus is much more on a specific habitat and for example, position of women in cities. In Republic period, in order to catch up with contemporary civilization, western civilization was set an example to reform the society. In accordance with this attitude, fundamental changes were made in family structure. Before the republic, the family institution was arranged according to religious principles, however, with the declaration of the Republic the family was arranged according to the government laws (Erder, 1984).

These types changed during the Republic period. The life styles become much more modern in some certain parts of the cities and even the family arrangements prevailed in conservative environments, marriage adds and marriage settlement companies appear in the cities. Giving adds to get married was a way before the Republic as well. "Saadet istihbarat Odas1" which was founded in 1930 and "Evlendirmeyi Kolaylaştırma Cemiyeti," founded in 1948, were some of the companies that offered a way to get married (Akçura, 2011). these institutions gathered people who wanted to marry for a certain fee and today, they still offer services, however in a different format with the new communication mediums.

Television channels and internet web-sites also draw the attention of advertisers and have high value as a platform as they have high ratings. In Today's Turkey, many big channels have programs and these programs arouse huge interest among the audience. In addition to television, the Internet also gathers people through marriage websites. Marriage institution, which has become a market nowadays, is going through a change because of the popular culture and new media mediums and processes that can be described as modern family arrangements become pervasive. 


\section{Data and Methods}

The research has been carried out on 315 participants in total, who were reached through a website providing online questionnaires. Among people who participated in the research, $\% 58$ of them were women, $\% 57$ of them were people in the age group between $18-24$, and $\% 70$ of them were people with bachelor's degree. While $\% 90$ of the participants stated that they are single, $\% 44$ of them declared that they have average incomes (between $1000 \mathrm{TL}$ and $3000 \mathrm{TL}$ monthly).

In the research, questionary method was utilized for data collection. In the questionnaire form, questions were related to the social networking sites participants are a member of, their purpose and frequency to join such web sites, whether they buy the product, advertisement of which they see on these websites and demographic data of the participants. In addition to these questions in the questionnaire form, a scale was utilized in order to determine the attitude of participants towards the concept of marriage.

In the research, a scale consisting of 4 questions was developed in order to determine the attitude of participants towards the concept of marriage. All the statements in the scale were organized in 5 point likert scale. According to this scale, high scores of the participants indicate that they have a traditional point of view towards marriage, and low scores indicates just the contrary. According to the results of factor analysis fort he scale, it has been confirmed that the scale involves single dimension $(=0,70$ Barlett's Test $=263,62 p<0,00)$ Cronbach's Alpha Value calculated for the scale indicated that the scale has internal consistency $(\alpha>0,60)$.

Table 1: Scale fort he Attitude Towards Marriage

\begin{tabular}{|l|l|}
\hline & Factor 1 \\
\hline It is not good to have a sexual intercourse before marriage & 0,80 \\
\hline $\begin{array}{l}\text { I am of the opinion that it is not good to share the same house before } \\
\text { marriage. }\end{array}$ & 0,78 \\
\hline I don't marry with a person my family doesn't approve & 0,74 \\
\hline $\begin{array}{l}\text { The person I am going to marry should have the reference of someone } \\
\text { I trust }\end{array}$ & 0,66 \\
\hline Cronbach's Alpha & 0,73 \\
\hline
\end{tabular}

$\mathrm{KMO}=0,70$ Barlett's Test $=263,62 \mathrm{p}<0,00$; Total Variance Explained $=\% 55,8$

\section{Findings}

According to the research results, $\% 97$ of the participants are a member of at least one social networking site. Among those websites, Facebook is the most prominent with more than half of the participants being the member of this site $(\% 64)$. Facebook is followed by Twitter with $\% 20$. Evlilikmerkezi.com, which provides service with the direct theme of marriage is followed by only $\% 2$ of the participants.

Table 2: Social Networking Sites Participants Are a Member of

\begin{tabular}{|l|l|l|}
\hline $\mathrm{n}=464$ & Frequency & Percent \\
\hline Facebook & 298 & 64 \\
\hline Twitter & 95 & 20 \\
\hline Yonja & 18 & 4 \\
\hline Hi5 & 14 & 3 \\
\hline Siberalem & 8 & 2 \\
\hline Evlilikmerkezi.com & 8 & 2 \\
\hline Others & 10 & 2 \\
\hline None & 13 & 3 \\
\hline
\end{tabular}


When the purposes of the participants in joining such social networking sites they are a member of were analysed, it has been observed that participants log in those sites mostly for "keeping in touch with their friends" $(4,11)$, "following the acquaintances and cathching up with what is going on" $(3,83)$ and "spending time" $(3,70)$. Participants declare that they log in those sites sometimes for "having fun, playing games" $(2,91)$ and rarely for "meeting new friends" $(2,17)$. Getting married $(1,48)$ or meeting someone for sexual intercourse, on the other hand, are options which are chosen by almost none of the participants. While the frequency of joining a social networking website for meeting someone to marry is generally low, rate of people who declare that they join a social networking with this purpose is $\% 7$.

Table 3: Purpose of the Participants for Joining Social Networking Websites

\begin{tabular}{|l|l|l|l|}
\hline $\mathrm{n}=315$ & $\mathrm{n}$ & $\mathrm{M}$ & $\mathrm{SD}$ \\
\hline Keeping in Touch with Friends & 299 & 4,11 & 0,99 \\
\hline $\begin{array}{l}\text { Following Acquaintances and Catching up with What } \\
\text { is Going on }\end{array}$ & 284 & 3,83 & 1,10 \\
\hline Spending Time & 287 & 3,70 & 1,19 \\
\hline Having Fun; Playing Games & 267 & 2,91 & 1,32 \\
\hline Meeting New Friends & 260 & 2,17 & 1,27 \\
\hline Meeting Someone for Marriage & 234 & 1,48 & 1,13 \\
\hline Meeting Someone For Having Sexual Intercourse & 229 & 1,43 & 1,06 \\
\hline Other & 26 & 2,30 & 1,51 \\
\hline $\begin{array}{l}\text { Frequency of Logging in to the Sites They are a } \\
\text { Member of }\end{array}$ & 314 & 3,94 & 1,12 \\
\hline
\end{tabular}

Participants were asked whether they paid any membership fee while joining the social networking sites they are a member of. According to the results, it is observed that almost all of the participants become a member of these sites without paying any fee. When participants were asked whether they buy any product, advertisement of which they see on the website they are a member of, it was observed that $\% 18,1$ of the participants buy a product because they see its advertisement on the website, which they are a member of,

Table 4: Paid Membership and Buying a Product, Advertisement of Which They See on the Website

\begin{tabular}{|l|l|l|l|}
\hline & & Frequency & Percent \\
\hline \multirow{2}{*}{$\begin{array}{l}\text { Paying a Fee While Becoming a Member of } \\
\text { Social Networking Site }\end{array}$} & Yes & 2 & 0,6 \\
\cline { 2 - 4 } & No & 313 & 99,4 \\
\hline $\begin{array}{l}\text { Buying a Product Because of Seeing its } \\
\text { Advertisement on the Website }\end{array}$ & Yes & 57 & 18,1 \\
\cline { 2 - 4 } & No & 258 & 81,9 \\
\hline
\end{tabular}

In order to indicae the effect of social media on marriage's becoming a market, whether people who becoma a member of a social media networking buy a product because they see its advertisement on the website was analysed. For this purpose, frequency values declared by the participants in terms of their purposes for logging in to the social networking sites were evaluated in two categories. Participants who state that their aim to join the website is "meeting someone to get married" are defines as "those whose aim to join the website is marriage", and participants who state that their aim is never or rarely to "meet someone for marriage" were defined as "those whose aim to join the website is not marriage". Participants whose aim to join the website is sometimes marriage, were not included in the analysis. 
The relationship btween participant's aim to join the website (meeting someone for marriage or otherwise) and whether the participants buy a product, advertisement of which they see on the website (whether the participants buy or not) was tested with chi-square analysis. According to the results of the analysis, it was observed that there is a significant relationship between these two variants $\left(\chi^{2}=6,43 ; p=0,01<0,05\right)$. Accordingly, it is observed that $\% 37,5$ of the participants who join a social networking website always or mostly for marriage declare that they buy a product because they see its advertisement on the website they are a member of. This rate is $\% 16,5$ in the participants who never or rarely join a social networking website for marriage (defined as those whose aim in joining a website is not marriage). The rate of the participants, whose aim in joining the website if marriage and who buy a product because of seeing its advertisement on the website is $\% 3,4$.

Table 5: People on Social Network for The Goal of Marriage Buying Products Because of the Advertisements of the Web Site

\begin{tabular}{|l|l|l|l|l|l|l|l|l|}
\hline & \multicolumn{3}{|l|}{$\begin{array}{l}\text { Buying a Product Because of seeing its } \\
\text { advertisement on the website }\end{array}$} \\
\hline & \multicolumn{3}{|l|}{ Buying } & \multicolumn{2}{l|}{ Not Buying } & \multicolumn{2}{l|}{ Total } \\
\hline The aim to join the website & F & $\%$ & F & $\%$ & F & $\%$ \\
\hline $\begin{array}{l}\text { Those whose aim to join the } \\
\text { website is marriage }\end{array}$ & 9 & 37,5 & 15 & 62,5 & 24 & 100,0 \\
\hline $\begin{array}{l}\text { Those whose aim to join the } \\
\text { website is not marriage }\end{array}$ & 39 & 16,5 & 198 & 83,5 & 237 & 100,0 \\
\hline Total & 48 & 18,4 & 213 & 81,6 & 261 & 100,0 \\
\hline$\chi^{2}=6,43 ; \mathrm{p}=0,01<0,05$ & & & & \\
\hline
\end{tabular}

In this research, the relationship between the participants' attitudes towards the concept of marriage and the frequency of their logging in the social networking websites in order to indicate the effect of social media on the institution of marriage. According to the results of correlation analysis, it is observed that there is a significant $(\mathrm{p}<0,05)$ but low $(\mathrm{r}=-0,13<0,40)$ relationship between the frequency of participants' logging in to the social networking websites and their attitudes towards the concept of marriage. This relationship in question is in a negative direction. Accordingly, as the frequency of participants' logging in to the websites increases, their traditional point of view towards the concept of marriage decreases. On the other hand, there is a proportinal, significant $(\mathrm{p}<0,05)$ but low $(\mathrm{r}=0,22<0,40)$ relationship between the frequency of participants' logging in to the social networking website/websites and their attitudes towards the concept of marriage. According to this result, we can suggest that people who take part in social networking websites for marriage maintain their traditional points of view.

Table 6: Relationship Between Frequency of Participants' Logging in Social Networking Sites and Their Attitudes Towards the Concept of Marriage

\begin{tabular}{|l|l|l|l|l|l|}
\hline & $\mathrm{N}$ & $\mathrm{M}$ & $\mathrm{SD}$ & $(1)$ & $(2)$ \\
\hline $\begin{array}{l}\text { (1) Frequency of his or her logging in the } \\
\text { website/websites he or she is a member } \\
\text { of }\end{array}$ & 314 & 3,94 & 1,12 & 1 & $-0,19^{* *}$ \\
\hline $\begin{array}{l}\text { (2) Frequency of his or her logging in to } \\
\text { the website/websites they are a member } \\
\text { of for meeting someone to marry }\end{array}$ & 234 & 1,48 & 1,13 & $-0,19^{* *}$ & 1 \\
\hline $\begin{array}{l}\text { (3) His or her attitude towards the } \\
\text { concept of marriage }\end{array}$ & 315 & 3,03 & 1,05 & $-0,13^{*}$ & $0,22^{* *}$ \\
\hline
\end{tabular}


$* \mathrm{p}<0,05 * * \mathrm{p}<0,01$

\section{Conclusion}

According to the rsearches and questionnares, it has been stated that invididuals' and societies' opinions about the marriage have changed. The research was based on Turkey and the questionnaire included in this research specified how the opinions about marriage have changed under the effect of technology and new media mediums. According to the research, it has been understood that matchmaking concept has now a new content due to the benefits that the new media medium offer. Another important finding is that marriage is one of the services on the internet. Under the light of this data, it can be claimed that formations based on friendship and marriages on various websites and in social media have turned marriage into a profitable market. Another finding of the research is that the traditional point of view about marriage in Turkish society has become modernized with the emergence of the internet, friendship websites and marriage websites. However, in some certain contexts, traditional attitude has not completely abolished; in some contexts traditional and modern views are blended.

\section{References}

Akçura,G.(2001). The History of Stuff I- Don’t Forget Me. İstanbul:Om yayınevi.(In Turkish).

Aktaş, C. (2007). 'The Comparison of New Media with Traditional Media.' G. Erol (ed.), Studies about Media, 108-120.İstanbul: Beta Basım. (In Turkish).

Bargh, J.A. \& K. Y. A. McKenna. (2004). 'The Internet and Social Life.' Annual Review Psychology: 573-590.

Telematics and Informatics 22(3): 161-180.

Brooks, M.(2011). 'How has Internet dating changed society? An Insider's Look ', Internet Dating Executive Alliance.

Cho,C.H. \& H.J. Cheon. (2004). 'Why Do People Avoid Advertising On The Internet?' Journal of Advertising 33(4):89-97.

Dijk, J.V.(1999).The Network Society.London: Sage Publications.

Ellison, N., R. Heino \& J. Gibbs. (2006). 'Managing Impressions Online: Self- Presentation Processes in the Online Dating Environment'. Journal of Computer Mediated Communication 11 (2).:415-441.

Erder, N.(1984). The Change of Family in Turkey - Analysis in terms of Legal Way, Ankara:Türk Sosyal Bilimler Derneği. (In Turkish).

Giddens, A.(1997). Sociology. Oxford.:Blackwell Publishers.

Lawson, H. M. \& K. Leck. (2006). 'Dynamics of Internet Dating.' Social Science Computer Review 24 (2):189-208.

Leung, L.\& P.S.N. Lee. (2004). 'Multiple determinants of life quality: the roles of Internet activities, use of new media, social support, and leisure activities.'

Parks, M. R. \& K. Floyd. (1996). 'Making Friends in Cyberspace.'Journal of Communication 46(1): 80-97.

Sezen, L.(2005). 'The Marriage Types in Turkey.'A.Ü.Türkiyat Araştırmaları Enstitüsü Dergisi. 11(27): 185-195. (In Turkish).

Selvi, E. Director of evlilikmerkezi.com. İstanbul: (07 April 2011).

Smith, A. D. (2005). 'Exploring online dating and customer relationship management.' Online Information Review 29(1): 18-33.

Thompson, J. B.(2008). The Media and Modernity. İstanbul: Kırmızı Yayın evi. (In Turkish).

Ozankaya, Ö. (2007). Sociology. İstanbul : Cem Yayınevi.(In Turkish).

Özdoğan, F.(2009). 'The Importance of Parner Choice in Marriage and Media..' Diyanet Aylık Dergisi. 38-39. 